\title{
DEBATES ACTUALES EN TORNO A LA PORNOGRAFIA Y A LA PROSTITUCIÓN
}

\author{
Raquel Osborne
}

«Aquellas feministas que quieren prohibir la pornografía están en contra de toda la industria del sexo; así pues, están en contra de nosotras las putas; a pesar de todo, nosotras somos feministas», manifestaba una prostituta canadiense, ${ }^{1}$ aun cuando semejante queja no tiene por qué circunscribirse únicamente a un país, sino que puede extenderse a una manera de entender ciertas formas de representación o comportamientos sexuales muy al uso dentro del feminismo. Pero, afortunadamente, las posturas dentro del mismo en relación a la pornografía y a la prostitución no son monolíticas, y ello es lo que propicia que exista un debate en curso, algunas de cuyas líneas maestras trataremos de exponer en estas páginas. Si bien la comprensión de ambos asuntos - pornografía y prostituciónestá interrelacionada, como demuestra la cita que acabamos de mencionar, trataremos los dos temas por separado, sobre todo porque cada uno de ellos posee una dinámica y un espacio propios en el ámbito del discurso feminista, al menos tal y como se ha desarrollado en los contextos que nos proponemos analizar aquí. No olvidemos, sin embargo, que uno y otro fenómeno conciernen a aspectos de la sexualidad femenina que, desde una óptica feminista, suelen connotar una especial degradación y explotación sexual de la mujer. Con todo, las controversias están llenas de matices y... Pero mejor vayamos por partes.

En relación con el tema de la pornografía, me propongo exponer so-

1. Gail Pheterson, The whore stigma. Female disbonor and male unwortbiness, Ministerie van Sociale Zaken en Werkgelegenheid, La Haya, 1986, p. 40.

7. 
meramente algunas discusiones que en torno a la misma han tenido lugar dentro del feminismo norteamericano en la presente década, pues el debate al respecto ha alcanzado en los EEUU unas cotas de intensidad muy altas y cobrado una virulencia que no le va a la zaga.

Las feministas norteamericanas encabezaron la búsqueda de una nueva definición sexual de la mujer tras el surgimiento de la revolución sexual de los años sesenta y de la segunda ola del movimiento feminista en los años setenta. Pero, como ya apuntamos, aquel feminismo se halla lejos de presentar una faz monolítica, y su postura no ha sido uniforme ante las nuevas circunstancias planteadas. Ante la nueva posibilidad de autoformularse la vieja pregunta freudiana en clave sexual: ¿qué desean las mujeres, sexualmente hablando?, o dicho con otras palabras: ¿en qué consiste la sexualidad femenina?, se han ido esbozando diversas respuestas a lo largo de los años, de acuerdo con las distintas percepciones de la posible sexualidad para las mujeres en una sociedad cambiante, sí, pero aún con fuertes tintes patriarcales.

Una primera respuesta la intentaron dar algunas lesbianas proponiendo una separación radical respecto al mundo masculino, con el fin de sustraerse a la influencia del patriarcado. Esta tendencia fue conocida como el separatismo lesbiano. La creencia de muchas de estas mujeres consistía en que, por el hecho de ser lesbianas, su sexualidad devendría automáticamente revolucionaria y antipatriarcal, toda vez que desafiaba la definición social de la sexualidad femenina como exclusivamente referida al hombre. Mas los problemas comenzaron a surgir enseguida. Algunas mujeres cayeron en la cuenta de que, contra todo pronóstico, no podían evitar, pongamos por caso, fantasías de violación. Las que pensaban que el tipo de actitud adoptada haría desaparecer en ellas cualquier vestigio de la cultura misoginista al uso se sintieron desilusionadas y hubieron de poner en cuestión sus concepciones. A su vez, las que nunca se habían creído demasiado aquello de que el separatismo llevaría a una transformación mágica de sus mentes acabaron por pensar que la franqueza amenazaba la solidaridad feminista, y cesaron de hablar de sus fantasías o de su sexualidad en general.

En realidad y durante varios años, prácticamente hasta 1981 -en que por primera vez se publican en un volumen de la revista Heresies $^{2}$ textos de diversas autoras en la línea que acabamos de mencionar-, el monopolio del discurso recayó casi exclusivamente en el movimiento antipornografía que se formó en la segunda mitad de la década de los setenta. El énfasis de este movimiento pasó de las agresiones reales contra las mujeres, como

2. Heresies, núm. 12, 1981. 
son los casos de violación y malos tratos, a la ideología que, en su opinión, promueve y epitomiza esta violencia: la pornografía, con sus imágenes de degradación y objetualización de la mujer. La pornografía no fue vista en su dimensión sexual, sino tan sólo bajo el rostro de la violencia. De esta manera, se unilateralizó la concepción de la sexualidad bajo su aspecto de riesgo, su faz peligrosa. Al mismo tiempo, y para distanciarse de toda aquella dimensión «no grata» de la sexualidad, se redefinió como «erótica» una sexualidad difusa, no genital, tierna, etc., que se dio en reputar como característica de las mujeres. Todo lo que no encajara en ese esquema -lo genital, la sexualidad separada del amor o de la relación estable, la dimensión de poder - se atribuyó a lo masculino 0 , cuando menos, al patriarcado. ${ }^{3}$ Por otra parte, y con vistas a aparecer más respetable ante una derecha cada vez más fortalecida, la tendencia de-sexualizadora se extendió a otros terrenos: el aborto fue defendido como un derecho legal antes que como un derecho a la libertad sexual: el lesbianismo se entendió como una amistad radical e íntima entre mujeres más bien que como una posibilidad de placer sexual, como una relación basada en una preferencia sexual.

Poco a poco, y tras el surgimiento de algunas voces aisladas en contra de este enfoque, comenzó a perfilarse, sobre todo a partir de 1981, una nueva facción del feminismo radical que se oponía a esta concepción diferenciadora de la sexualidad masculina y femenina, y se negaba a proclamar como superior a esta última, reivindicando el derecho de las mujeres a experimentar y descubrir nuevas vías, si bien heterodoxas, para su sexualidad, e incluso el de explorar terrenos tradicionalmente vedados a las mujeres, como podría ser una «pornografía» hecha por ellas mismas. Frente a la postura del movimiento antipornografía, la tendencia «prosexo», como se ha dado en llamarla, ha querido contraponer la cuestión del placer de las mujeres al análisis exclusivo de las mujeres como víctimas. Como señalaba una de sus portavoces, «la sexualidad es simultáneamente un terreno de restricción, represión y riesgo, así como también de exploración, placer y acción. Pensamos que esta doble dimensión es importante, ya que hablar solamente de placer y gratificación conduce a ignorar la estructura patriarcal en que actúan las mujeres, pero a la vez referirse únicamente a la violencia sexual y a la opresión conduce a ignorar la experiencia de las mujeres en su elección y actividad sexuales, e inconscientemente incrementa el terror sexual y la desesperación en que éstas

3. Para un análisis más detallado de esta concepción, véase mi trabajo «El discurso de la diferencia: implicaciones y problemas para el análisis feminista», Desde el feminismo, número cero, diciembre de 1985, pp. 30-43 y 69 . 
viven». ${ }^{4}$ Este tipo de discursos fue tachado de no feminista por el movimiento antipornografía, lo que, junto a la confusión inicial reinante, provocó que los escritos representados por la corriente pro-sexo no fueran aceptados inicialmente en la Prensa propiamente feminista, sino en las secciones de feminismo de la Prensa homosexual y en la de izquierdas. Cuando por fin la corriente que ahora estamos analizando rompió aguas, no lo hizo sin traumatismos. Su bautismo de fuego tuvo lugar durante el simposio sobre sexualidad que se realizó en 1982 en el Barnard College de la Universidad de Columbia, en Nueva York, cuando por primera vez se reunieron en un marco académico las feministas universitarias con las que militaban en diversos grupos y representaban diferentes tendencias de signo heterodoxo en cuanto a la sexualidad, en un intento de actualizar el conocimiento y la experiencia que alrededor de esta temática estaban viviendo varios sectores de mujeres, los cuales no se habían podido expresar hasta entonces de una forma coherente. Representantes del movimiento antipornografía propugnaron el boicot más absoluto a este simposio, quizá porque significaba el fin del monopolio de su discurso feminista sobre la sexualidad, y se llegó a graves enfrentamientos ${ }^{5}$ que no pudieron impedir la publicación de dos volúmenes relacionados con el simposio, el ya citado Diary of a Conference on Sexuality y, más tarde, el de Pleasure and Danger: Exploring Female Sexuality (1984), que, junto con otro aparecido entretanto, Powers of Desire (1983), ${ }^{6}$ significaron un serio intento de unir la experiencia sexual de grupos de mujeres, en su vida diaria, con investigaciones académicas de carácter histórico y sociológico, en orden a reafirmar el derecho de las mujeres a una sexualidad libre y autónoma. Tal búsqueda de nuevas vías no dejará de encontrar dificultades y problemas, por cuanto se reivindica el derecho al placer sexual como fuente importante de gratificación para las mujeres, sin excluir en esta búsqueda fórmulas heterodoxas como la pornografía, las relaciones de butch/femme ${ }^{7}$ y las sadomasoquistas entre mujeres, así como la posibilidad de separar el

4. Carole S. Vance, "Concept Paper: Towards a Politics of Sexuality», en Hannah Alderfer, Beth Jaket y Marybeth Nelson, comps., Diary of a Conterence on Sexuality, Nueva York, 1982, p. 38.

5. Sobre el significado y los acontecimientos acaecidos en torno a este simposio, véase el capítulo "La sexualidad como punto de ruptura», incluido en mi libro La encrucijada de la sexualidad, de próxima publicación.

6. Carole Vance, comp., Pleasure and Danger, Routledge \& Kegan Paul, 1984, y Ann Snitow, Christine Stansell \& Sharon Thompson, Powers of Desire, Nueva York, Monthly Review Press, 1983.

7. Se me ocurre hacer una sugerencia para una posible traducción de estos términos: puesto que la correspondencia más aproximada con el término butch en nuestro idioma sería el de marimacho, cabría acuñar el término marihembra para su 
sexo del amor, o la de la promiscuidad... todas ellas tradicionalmente mal vistas desde la ortodoxia del otro sector.

Ante la llamada a la censura de materiales considerados pornográficos por parte de la corriente que se opone tajantemente a los mismos, la tendencia pro-sexo ha publicado, entre otros, dos volúmenes respectivamente titulados Women Against Censorship y Pornograpby Notebook, ${ }^{8}$ dedicados ambos tanto a analizar el fenómeno de la pornografía como a señalar los peligros que para el movimiento feminista entraña cualquier postura que pretenda recurrir a las leyes para combatir la manifestación de fantasías sexuales primordialmente masculinas, por muy controvertibles que éstas nos parezcan.9 Se denuncia asimismo la posibilidad de apropiación por parte de la Nueva Derecha - the New Rigth- de algunos de los planteamientos e iniciativas del movimiento antipornografía, con lo cual el conjunto de las mujeres acabaría perdiendo parte del terreno que tanto ha costado ganar a lo largo de todos estos años de lucha.

El enfrentamiento entre ambos grupos es prácticamente total hasta la fecha, y por ende ha dividido al feminismo. Pero, a la vez, ello ha contribuido a abrir un debate sobre el alcance y las posibilidades de la sexualidad para las mujeres en los años ochenta, así como acerca de si el feminismo se halla autorizado a determinar cuál debe ser la correcta sexualidad para las mujeres, o más bien acontece que no existe tal corrección; mientras que, por el contrario, cualquier tipo de restricciones podría llevar a limitar intolerablemente nuestra capacidad de enriquecimiento sexual y, en definitiva, humano.

En cuanto al tema de la prostitución, el asunto es francamente complicado, pero ante todo por la actitud inhibitoria que suelen adoptar los grupos sociales progresistas, incluidas las feministas. En dicha actitud priman la incomprensión, el moralismo, el paternalismo y el redentorismo, manteniéndose una distancia tal con respecto a la prostituta y a su entorno, que la prostitución permanece como una cuestión abstracta, totalmente al margen de nuestras vidas y a la que despachamos con la constatación de

correlativo femme. Tan arbitrarios -o pertinentes- podrían ser el uno como el otro. De todas formas, podríamos describir las relaciones del tipo butch/femme como aquellas en las que las dos mujeres de una pareja lesbiana representan, al menos formalmente hablando, roles claramente diferenciados que podemos identificar como masculino y femenino, respectivamente.

8. Varda Burstyn, comp., Women Against Censorbip, Douglas \& McIntyre, 1985; y Pornograpby Notebook, comp. por FACT -Feminist Anticensorhip Taskforce-, Nueva York, 1986.

9. Para más información, véase el capítulo «Censura o libertad de expresión, ¿un dilema para el feminismo?», en Raquel Osborne, La encrucijada de la sexualidad, op. cit. 
que se trata de un asunto espinoso. La lógica consecuencia es una profunda ignorancia acerca de cuál puede ser el modo de pensar y de sentir de las propias prostitutas o, en el mejor de los casos, una atención prestada sólo a aquella parte del discurso que se está predispuesto a oír y que concuerda con nuestras apriorísticas creencias. Las políticas públicas que se siguen en relación con la prostitución dependen estrechamente de lo que de ella se opine, y por ello resulta fundamental repasarlas sumariamente.

Del probibicionismo sólo nos interesa su mención: pretende eliminar la prostitución a base de represión, y señalaremos únicamente que es la política seguida en los Estados Unidos (excepto en el Estado de Nevada). El reglamentarismo parte del reconocimiento de la prostitución como una realidad innegable y funcional, que contribuye a preservar el orden en la familia tradicional y en la sociedad bienpensante. Como se teme que la prostituta contamine por vía venérea a los varones que la frecuentan, se pretende ejercer sobre ella un control sanitario obligatorio, permitiéndose sobre todo la práctica de la prostitución en el burdel. Pero no se ha dejado de observar que en muchas ocasiones ello supone la negación del derecho a la libre elección del cliente y al libre movimiento de la prostituta, pues a menudo se le restringe el derecho al libre desplazamiento.

El abolicionismo nos interesa más porque a él responde la política oficial española, tanto la franquista como la de nuestros mismos días, así como porque constituye la postura casi unánimemente defendida por el feminismo. Desde el abolicionismo se pretende básicamente la reforma de las prostitutas, el castigo para los chulos y proxenetas y la disuasión de los clientes. En aras de una defensa de la «dignidad» de las prostitutas y de su protección frente a la degradación que sufren por su actividad, se intenta, paradójicamente, liberarlas de su trabajo por medio de la eliminación de este último. Así entendidas las cosas, nadie se plantea la reivindicación de ciertos derechos para las prostitutas, ya que, se arguye, ello significaría la legitimación de una situación discriminatoria para la mujer. Por los mismos motivos que no se acepta la consideración de semejante actividad como una profesión, sino que es más bien juzgada, explícita o implícitamente, como una actividad vergonzosa y vergonzante, que solamente requiere nuestros esfuerzos políticos con el fin de obtener su erradicación. Así, la prostitución «es percibida como la máxima objetualización de las mujeres y la máxima alienación en el trabajo. Por tanto, las putas son consideradas como las víctimas prototípicas del patriarcado y del capitalismo. La adquisición de poder por su parte resulta, según este análisis, una contradicción ideológica». ${ }^{10}$

10. Pheterson, op. cit., p. 38 . 
Sin embargo, las prostitutas reunidas en el Congreso Internacional celebrado en los locales del Parlamento Europeo en 1986 no opinaban lo mismo, sino que más bien criticaban esta posición. «Históricamente - se lee en la resolución final elaborada por el Comité Internacional en favor de los derechos de las prostitutas en dicho Congreso-, los movimientos de mujeres se han opuesto a la institución de la prostitución, mientras que proclamaban su apoyo a las mujeres prostitutas. Sin embargo, las prostitutas rechazan un apoyo que requiere de ellas el abandono de la prostitución; asimismo, se oponen a ser tratadas como símbolos de opresión y piden su reconocimiento en tanto que trabajadoras.» Señalan además que, debido a las dudas o al rechazo por parte de las feministas a aceptar la prostitución como un trabajo legítimo y a considerar a las prostitutas como mujeres trabajadoras, la mayoría de las prostitutas se han sentido muy alejadas del feminismo. Añadiendo que mientras la prostitución no sea redefinida como un trabajo legítimo, las prostitutas no lograrán ser consideradas auténticas ciudadanas ni gozar de los mismos derechos que aquéllas. Todo ello viene enmarcado, por supuesto, en la afirmación del derecho de todas las mujeres -inexistente hoy por hoy-- al acceso a todas las posibilidades educativas y laborales y a la debida remuneración y respeto en cualquier ocupación, incluyendo la prostitución. Por último, los juicios morales que se esconden tras la postura abolicionista son impuestos a las prostitutas por medio de su supuesta rehabilitación o de la persecución de sus asociados, independientemente de cuál sea su conducta y de si son voluntariamente aceptados como tales o no por las interesadas."

Considerando, pues, injustas y arbitrarias las medidas represivas, y dando por sentada la necesidad de medidas preventivas y de re-cualificación profesional para quienes así lo deseen, la Carta Mundial de los derechos de las prostitutas, adoptada en el primer Congreso Internacional de las mismas celebrado en Amsterdam en 1985, pide que se reconozca la legitimidad del ejercicio de la prostitución y de las personas que a ella se dedican.

Recogiendo este tipo de sugerencias, el Parlamento Europeo adoptó, en una resolución sobre la violencia contra las mujeres en 1986, las siguientes recomendaciones, entre otras: fesión).

- Despenalizar el ejercicio de esta profesión (nótese que se dice pro-

11. Second World Whore's Congress, «Statement on Prostitution and Feminism», International Committee for Prostitutes' Rights, Parlamento Europeo, Bruselas, 14 de octubre de 1986. 
- Garantizar a las prostitutas los derechos que disfrutan el resto de los ciudadanos.

- Ayudar y fomentar los grupos de autoasistencia formados por prostitutas y sensibilizar a la policía y al poder judicial sobre la necesidad de mejorar la protección de las prostitutas que deseen presentar denuncias contra los chulos, con el fin de reducir su temor a ser amenazadas por éstos.

Se añadía asimismo que «cuando se estuvieran discutiendo medidas legales sobre prostitución, las mujeres a quienes conciernen deberían estar incluidas en las deliberaciones».

La principal conquista en todo esto es el reconocimiento del derecho, y aun la necesidad de que las prostitutas se autoorganicen y planteen, desde su propia experiencia, una plataforma reivindicativa. Ante la despenalización todo el mundo está de acuerdo, pero hay que ir más allá. ¿Cómo conseguir que mejoren sus condiciones de trabajo, que la policía sirva para protegerlas y no como una nueva fuente de amenaza, si toda la actividad que rodea a la prostituta está criminalizada? Resulta cuanto menos «ridículo y deshonesto el mezclar la prostitución consciente y adulta con la infantil, con la esclavitud y la explotación» que ciertamente abundan en este terreno, «con la fuerza, la violencia y el engaño» que impiden la libertad y la integridad de la prostituta. ${ }^{12} \mathrm{Y}$ ante la acuciante necesidad de cobertura sanitaria y de pensión de vejez, dos flagrantes problemas en este sector, ¿cómo negarles el acceso a la Seguridad Social en condiciones de igualdad con el resto de los trabajadores? ¿Quizá porque no se puede reconocer su trabajo como el de las demás personas? ¿Cómo aceptar cualquier decisión legislativa si ellas no están presentes y exponen su voz? ¿Quizá porque la política seguida es la de «todo para el pueblo pero sin el pueblo»? ¿Dónde estaban, por otra parte, las organizaciones progresistas, feministas incluidas, cuando las prostitutas de Barcelona se manifestaron en 1985 con la intención de formar un sindicato o asociación?

Todo parece indicar un escaso interés real por parte de las instituciones del Estado o de organizaciones progresistas en torno a esta problemática. Dos ejemplos nos servirán como muestra. En las jornadas que sobre prostitución organizó el Ayuntamiento de Madrid en marzo de 1987, el presidente de la Asociación Pro Derechos Humanos, José Antonio Martín Pallín, presentó una ponencia titulada «La prostitución, entre la represión y los derechos humanos», en la que examinaba la influencia negativa de una política directamente represiva o moralista en la posibilidad, no

12. «Abolitionists Threaten the Human and Civil Rights of Prostitutes!!!», International Committee for Prostitutes Rights, Press Release, 15 de septiembre 1987. 
ya de la consecución, sino simplemente de la formulación de los derechos humanos para las prostitutas. Sin embargo, en el Informe anual sobre los derechos bumanos en España, referido al año 1987 y publicado en fecha reciente por la citada asociación, no hay una sola mención de la violación o la ausencia de estos derechos humanos en el caso de las prostitutas. Se ve, pues, que la Asociación que Martín Pallín preside aún no ha tomado en consideración como parte de su actividad el tema de los derechos humanos de este colectivo.

El otro caso que quería citar se refiere, en lo que a la prostitución atañe, al Plan para la igualdad de oportunidades de las mujeres, 1988-1990 propuesto por el Instituto de la Mujer. Se justifica en aquel apartado el abolicionismo oficial en el país en virtud de la ratificación por España de un Convenio Internacional en 1952 (véase que corrían las fechas más oscuras del franquismo), afirmándose, cómo no, que la prostitución «no es una opción de vida libremente elegida y conduce a quien la ejerce a una situación límite de explotación a nivel psicológico, social y económico». Aun cuando se reconoce que las prostitutas viven uen condiciones nada acordes con los derechos que, para todos los ciudadanos, reconoce la Constitución», se propone como toda propuesta en este terreno «una atención decidida a favor de quienes ejercen la prostitución, con objeto de lograr que estas personas disfruten de condiciones de vida normales $y$, sobre todo, para posibilitar el libre abandono de su situación» (subrayado nuestro). No se mencionan en ninguna parte las recomendaciones sobre la prostitución adoptadas por el Parlamento Europeo en 1986, tal vez justificando esta omisión por el hecho de que son eso, recomendaciones que no obligan a nada. Pero de esa forma el conjunto de los españoles permanece ignorante acerca de cuáles son las últimas directrices de un Parlamento en el que España participa y, por supuesto, se justifica el silencio en torno a los derechos de las prostitutas, comenzando por su derecho a la autoorganización, y la negativa a considerar su actividad como una profesión, etc. En definitiva, el Instituto de la Mujer margina a, y se margina de, las prostitutas.

Por otra parte, el mismo Instituto ha ayudado a financiar al menos dos estudios sobre prostitución en los últimos años. A pesar de ello, existe la impresión generalizada entre las mujeres, presumiblemente compartida por el Instituto, de que o apenas se ha hecho nada en este sentido, o de que lo que se ha hecho es más bien malo. Veamos, pues, qué es lo que se ha hecho. El estudio realizado por la Fundación Solidaridad Democrática en 1985-86, ${ }^{13}$ deja bastante que desear si tenemos en consideración que

13. La prostitución en la mujer: una forma de marginación. Estudio sociológico, 
abarca una muestra de numerosas comunidades autónomas, que tenía a su disposición toda la infraestructura de Solidaridad -dedicada precisamente a atender a la marginación de la mujer - y que contaba con una generosa financiación. Pero habría que mencionar, no obstante, algunos puntos de interés. Es cierto que el tipo de preguntas realizadas, la importancia que se les concede y el análisis que se extrae de las respuestas limitan en buena medida los logros del trabajo. Ello no obstante, y dada la escasez de datos autóctonos al respecto, el trabajo proporciona una información que con otro tipo de orientación - por ejemplo, centrándola en torno a los derechos de las prostitutas- podría muy bien ser aprovechada en favor de las mismas, dado que al fin y al cabo, y pese a las insuficiencias de un estudio como éste, las prostitutas tienen en él al menos la ocasión de expresar sus opiniones.

Por otra parte, el estudio llevado a cabo por Carmen Vázquez y Rosa M. Andrieu, titulado Situación de la marginación de la mujer: la prostitución en España (Bilbao, 1984-85), curiosamente infravalorado por lo que puedo colegir del hecho de no haber sido publicado, es de lo mejorcito que se ha llevado a cabo, en términos empíricos, sobre prostitución en nuestro país. Podríamos destacar en él la general ausencia de carga moralista y su completo análisis de todos los sectores de mujeres implicados, lo que permite ofrecer una visión plural de nuestro fenómeno. Deberíamos dejar de considerar como malo todo lo autóctono -prejuicio acaso que ha impedido la publicación de este trabajo, que merecería por todos los conceptos ver la luz en letra impresa- y como bueno todo lo que nos viene de fuera, que es lo que ha propiciado, para «compensar nuestras lagunas», la publicación, co-financiada por el Instituto de la Mujer, del libro de Kathleen Barry, Esclavitud sexual de la mujer, ${ }^{14}$ texto a no desdeñar, desde luego, pero cuyo interés para el conocimiento del fenómeno de la prostitución, tanto en su vertiente teórica como empírica, no supera en modo alguno al que presenta el estudio que acabamos de mencionar, sobre todo porque este último se refiere a la realidad española de aquí y ahora. No obstante, y de pensar en dar a conocer en español algunos textos extranjeros - tarea por lo demás absolutamente necesaria-, hubieran resultado más interesantes, a mi juicio, los libros de Judit Walkowitz, Prostitution and Victorian Society: Women, class, and the state; de Ruth Rosen, The Lost Sisterbood. Prostitution in America, 1900-1918, ambos de ca-

1985-1986. Realizado para la Fundación Solidaridad Democrática por Ana Santamaría, Balti Martínez Toledano y María Espinosa.

14. Kathleen Barry, Esclavitud sexual de la mujer, Barcelona, LaSal, Edicions de les Dones, 1987. 
Debates actuales en torno a la pornografía y a la prostitución

rácter histórico; ${ }^{15}$ o el muy reciente y antes citado de Gail Pheterson, The whore stigma. Female dishonor and male unworthiness, en línea con el nuevo enfoque a favor de los derechos humanos de las prostitutas que aquí se ha pretendido exponer, siquiera sea someramente.

En suma, pues, una determinada manera de entender el fenómeno de la prostitución está condicionando, en mi opinión, no sólo la política o el interés general sobre el tema, sino la pobreza entre nosotros de un debate caracterizado, entre otras cosas, por la falta de una decidida actividad editorial que dé a conocer lo más granado de la producción, propia o ajena. Si carecemos de información, difícilmente podremos, no ya formarnos un juicio acerca de éste y otros problemas conexos, sino ni tan siquiera liberarnos de nuestros prejuicios.

15. Walkowitz, Judith R.; Prostitution and Victorian Society: Women, class, and the state, Cambridge University Press, 1980; y Rosen, Ruth, The Lost Sisterbood. Prostitution in America, 1900-1918, Johns Hopkins Paperbacks edition, 1983. 